\title{
Catalytic Cracking of Vacuum Gas Oil and Used Lubricating Oil on Oil Shale Ash
}

\author{
Omar Al-Ayed ${ }^{*}$
}

\begin{abstract}
Al-Balqa Applied University, Faculty of Engineering Technology, Department of Chemical Engineering, Marka 11134 Amman Jordan
\end{abstract}

\begin{abstract}
In this research, Vacuum Gas Oil and/or used lubricating oil is subjected to thermal cracking (pyrolysis) after impregnation on oil shale ash to obtain lighter molecular weight components. The spent oil shale of the thermal cracking step is subjected to further heat treatment in open air at $950^{\circ} \mathrm{C}$ to react any organic compounds and mineral carbon to metal oxide. Used and/or fresh lubricating oils are impregnated on oil shale ash particles. Ash is soaked for 24 hours to allow absorption of the VGO or lubricating oils into the pores of the ash material. Oil shale ash which is known to contain several metal oxides such as $\mathrm{CaO}, \mathrm{SiO}_{2}$, and lesser quantities of $\mathrm{Fe}_{2} \mathrm{O}_{3}, \mathrm{Al}_{2} \mathrm{O}_{3}, \mathrm{~K}_{2} \mathrm{O}, \mathrm{Na}_{2} \mathrm{O}$, etc. possesses inherent catalytic nature to crack heavy hydrocarbons to produce lighter components.

The absorbed Vacuum Gas Oil and/or lubricating oil inside the pores of the oil shale ash, is allowed to crack at $600^{\circ} \mathrm{C}$ temperature. Cracking of VGO is conducted in a fixed bed reactor under nitrogen, steam environments. The weight ratio of the absorbed oil into the pores to oil shale ash is $1: 1$ ratio.

The particle size was in the range of $20-25 \mathrm{~mm}$. The liquid products indicated 20 vol\% falls in the kerosene fraction specifications where as Approximately $50 \mathrm{vol} \%$ is diesel cut. Residue which boils at higher than $370{ }^{\circ} \mathrm{C}$ constituted about $30 \mathrm{vol} \%$ of the liquid distillate.

Steam presence in the reaction media affected the composition of the product as measured in density increase. The sulfur content of the produce is found to be $0.75 \mathrm{wt} \%$.
\end{abstract}

Keywords: Cracking, lubricating oil, oil shale ash, fractionation, catalyst.

\section{INTRODUCTION}

Crude oils contain a large fraction of heavy products for which only few outlets exist. Indeed, the world demand for light and middle distillate continually increases, while at the same time, the available crude oil becomes heavier [1]. Therefore, upgrading of heavy crude oil fraction to more useful lighter products is indispensable. Hydrocracking and hydrotreating are the most important processes in a modern refinery to produce low sulfur diesel. The versatility and flexibility of the process makes it economically attractive to convert different types of feedstock into various yields including gas, LPG, naphtha, kerosene and diesel, leading to its widespread applications.

Millions of barrels of waste automobile lubricating oil are generated every year in the world. Some of the technologies successfully applied the operation of regenerating plants and obtained the re-refined lubricating oil, which has equivalent quality to the new lubricating oil [2-4]. Kim et al. [5,6] investigated a novel technology for obtaining more valuable product oils from the waste lubricating oils. The waste lubricating oils were mixed with atmospheric distillation residuum

*Address correspondence to this author at the Al-Balqa Applied University, Faculty of Engineering Technology, Department of Chemical Engineering, Marka 11134 Amman Jordan; Tel: +962 6 4790333; Fax: +962 6 4790350;

E-mail; omar.alayed@bau.edu.jo,omar.al-ayed@jordanoilshale.net from crude oil and then were distilled under a vacuum. These methods of disposal are no longer practicable, because these treatment processes have several problems such as low yield, environmental pollution and sludge disposal. Therefore, it is necessary to seek a suitable method to solve the disposal problems.

Many pyrolysis studies have been applied to organic materials such as coal, waste tires, waste plastics, waste woods, and oil shales [7-9]. Pyrolysis process has certain advantages over other treatment methods of waste disposal [7, 10, 11]. [Pyrolysis products such as gases, liquid oils and char can be used as fuels. Some studies have elucidated the mechanism of the degradation of organic materials. Ballice et al. [11] and Prakash [12] proposed a combined parallel and series reaction scheme for the pyrolysis mechanism of oil shale. Waste oils are an excellent example of a high-volume waste that can be processed into valuable products [13-14]. Pyrolysis may be one option for conversion of waste oils into a more useful product and has received special attention due to the multiphase product variation with different yields in solid, liquid and gas form depending on the process conditions.

Large and increasing volumes of used lubricating oil are produced each year that, after use, are considered hazardous wastes. The used oils are disposed in many 
ways including incineration, land spreading, and dumping on the ground and into water [15]. All used oil eventually creates environmental hazards. However, combustion and incineration of wastes is often difficult and cleaning of flue gases is complex and expensive because they contain important quantities of contaminants. As a solution to this problem of disposal, waste lubricating oil could be collected and processed via a re-refining process to become "re-refined lubricating oil" with an equivalent quality to new lubricating oil [16] or via direct upgrade from thermal cracking or catalytic cracking. In thermal cracking, hydrocarbons with higher molecular weight in lubricating oils can be transformed to lighter hydrocarbon products by thermolysis at higher temperature.

These lubricating oils are long chain hydrocarbon molecules, which can be converted to light hydrocarbons, by using many types of catalysts. HZSM-5 was determined to be most efficient in the oil cracking processes of organic liquid fuel production that give mainly aromatic hydrocarbons [17]. The recycling of waste lubricant oil from automobile industry was found to be best alternative to incineration [18]. Silica $\left(\mathrm{SiO}_{2}\right)$, alumina $\left(\mathrm{Al}_{2} \mathrm{O}_{3}\right)$, silica-alumina $\left(\mathrm{SiO}_{2}\right.$ $\mathrm{Al}_{2} \mathrm{O}_{3}$ ) supported iron oxide (10 wt $\% \mathrm{Fe}$ ) catalysts were prepared by wet impregnation method and used for the desulphurisation of waste lubricant oil into fuel oil.

Cracking catalysts have been used to obtain a high proportion of gasoline product from heavy reactants. Commercial fluid cracking catalysts consist of zeolite as a main component and silica-alumina as a matrix. Since both zeolite and matrix must be stable at high temperature, zeolite may be modified by a steam or acid treatment in order to de-aluminates. In cracking of hydrocarbons, several investigations indicated the importance of catalyst size and pore size distribution [19]. These authors studied the cracking of hydrocarbons on zeolite with different pore sizes, and the cracking of 1-phenylheptane over zeolite $\mathrm{Y}$, beta, mordenite, ZSM-5 and silica alumina. They reported that bi-cyclic products were influenced by the pore size of zeolite. Also the product distribution in gasoline range obtained from the cracking reaction of heavy oil containing a high proportion of linear paraffin. However, for vacuum gas oil containing various kinds of higher hydrocarbons such as polyaromatics, naphthenes and alkanes, there are not many studies relating to the difference in product distribution resulting from cracking [20]. Cracking catalyst allows a conversion of heavy oil into lower boiling fraction such as gasoline, kerosene and diesel. It is well known that the activity and the product distribution in catalytic cracking of hydrocarbon are affected type and changes in both matrix and main component of catalyst

Used lubricating oil is a very complex mixture of low and high $\left(\mathrm{C}_{15}-\mathrm{C}_{50}\right)$ molecular weight aliphatic and aromatic hydrocarbons [16], additives, metals, and various organic and inorganic compounds. The chemical composition of used lubricating oil varies widely and depends on the original crude oil, the processes used during refining, the efficiency and type of engine that utilized the oil, products of gasoline or diesel combustion, the additives added to the fuel and to the original oil, and the length of time that the oil remains in the engine. Used lubricating oil has a density (at $20{ }^{\circ} \mathrm{C}$ ) of about $0.88 \mathrm{~kg} \mathrm{~L}^{-1}$. Lube oils are designed to withstand very high service temperatures in the internal combustion engines and resist thermal degradation.

In view of the need to develop commercially practicable processes for deriving liquid fuels from waste automobile lubricating oil, a description of pyrolysis kinetics is necessary for reactor design and scale-up.

\section{EXPERIMENTAL PROCEDURE}

\subsection{Part one: Soaking and Sample Preparation}

The raw oil shale material obtained from Ellajjun mine south of Amman are crushed and sieved to fractions between $20 \mathrm{~mm}$ and $25 \mathrm{~mm}$. Oil Shale was subjected to destructive distillation in a fixed bed reactor to remove shale oil. The extracted oil shale is termed "spent shale" shown in picture 1 , in which traces of solid carbon "fixed carbon" remain pyrolyzed in addition to mineral carbon present as calcium and magnesium carbonate. During pyrolysis step, which is accomplished at $550{ }^{\circ} \mathrm{C}$, volatile matter, moisture, and some hydrocarbons evolved as vaporous products. In order to ensure the conversion of all minerals present in the oil shale to metal oxides, a calcination step is necessary.

The catalytic effect is effected by the oxides of silicon, aluminum, and ferrous as major cracking catalyst. The spent shale is placed in an oven operated at $950{ }^{\circ} \mathrm{C}$ for a minimum period of 4 hours or more to ensure the transformation of all minerals to their oxides. Picture 2 shows the oil shale ash after calcination step. The calcination step ensure carbonate 
decomposition to free carbon dioxide from dolomites that results in increasing the porosity of the ash to more than $50 \%$. Upon the completion of the calcination step, the ash is ready for the second step in the experimental procedure.

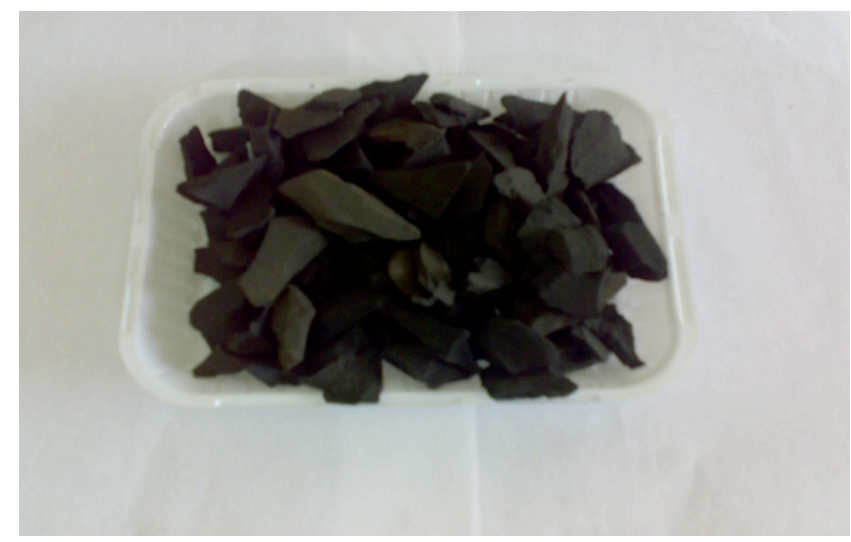

Picture 1: Spent shale after pyrolysis and before calcination.

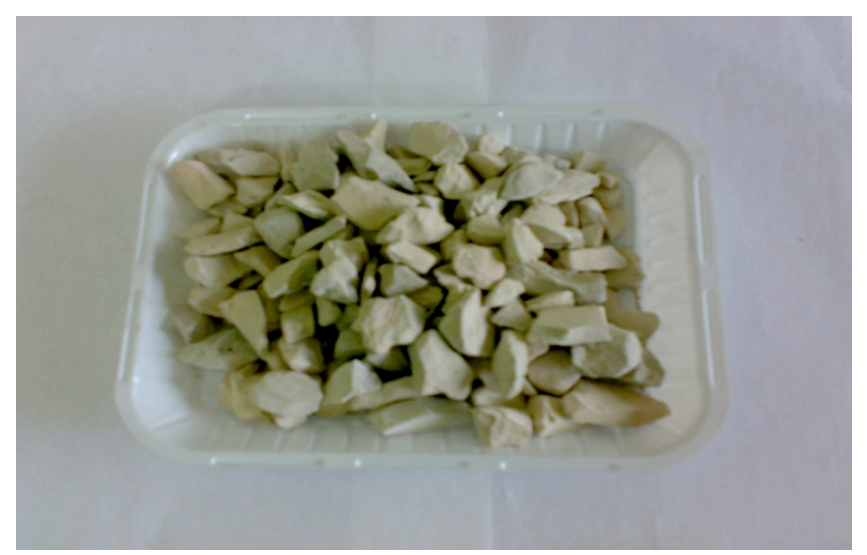

Picture 2: Ash (spent shale after calcination at $950{ }^{\circ} \mathrm{C}$ ).

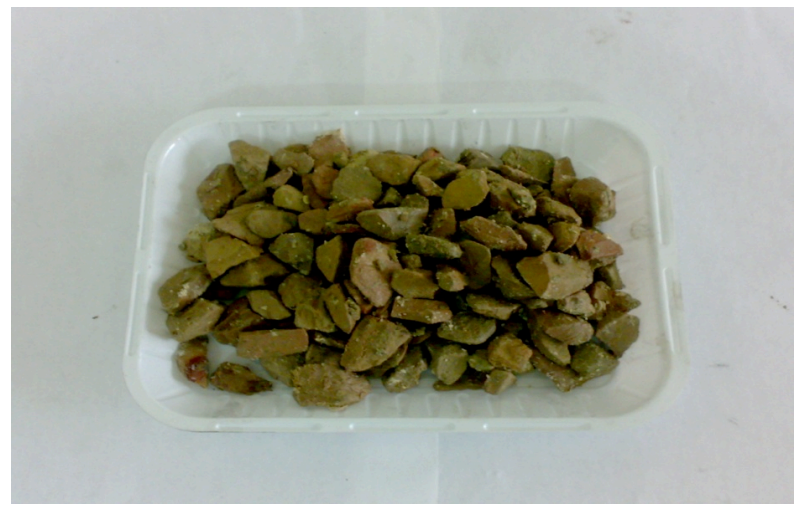

Picture 3: Soaked ash in fresh oil lubricating oil.

Calcined ash was soaked in fresh or used lubricating oil according to experimental requirement for a period of twenty four hours at room temperature and atmospheric pressure, then the excess non- absorbed oil was removed. The weight percentage of absorbed oil into ash to that of fresh ash at these conditions was calculated, and found to be 1.0:1.0. Pictures $\mathbf{3}$ and $\mathbf{4}$ show the soaked ash after impregnation with fresh and used lubricating oils respectively.

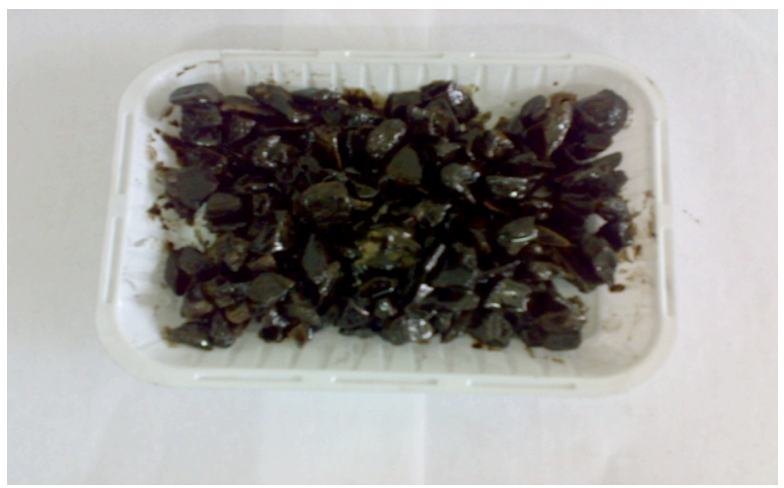

Picture 4: Soaked ash in used lubricating oil.

\section{APPARATUS DESCRIPTION}

As shown in picture 5 , the apparatus consists of the retort: A cylindrical tube with $5 \mathrm{~cm}$ diameter and $20 \mathrm{~cm}$ height. The available free volume is estimated to be $800 \mathrm{~cm}^{3}$ with downward conical end. The retort has a bottom screwed opening for charging/discharging purposes and two inner $8 \mathrm{~mm}$ side tubes to preheat nitrogen sweep gas which contact sample at bottom of reactor to sweep products in the upward direction. The top outlet is connected directly to condenser. Temperature controller cum indicator is used for monitoring and controlling experimental conditions.

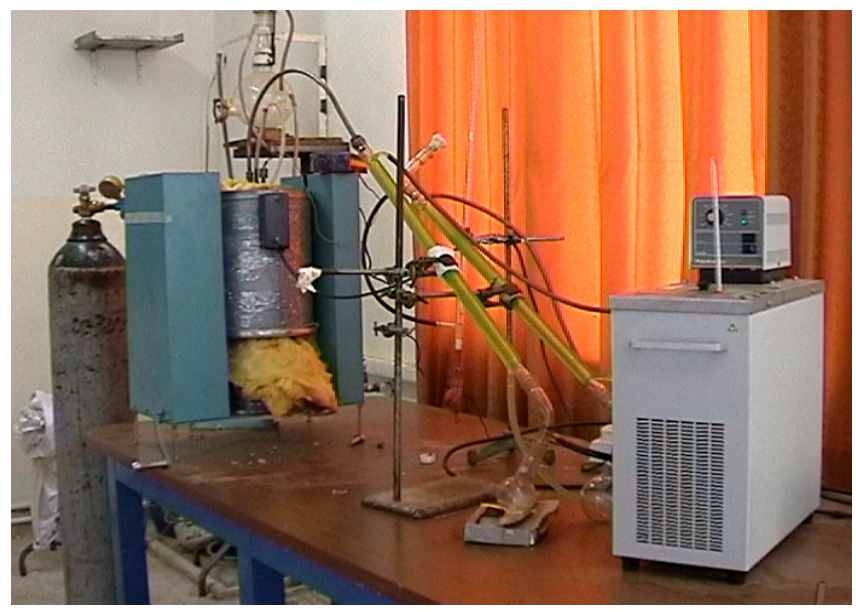

Picture 5: Experimental apparatus.

\subsection{Part two: Cracking Runs}

In order to measure the amount of cracked oil and/or evaporated during run, a known weight of ash impregnated oil is placed in the retort in nitrogen 
environment to ensure pyrolysis operation. The sweeping gas flow rate through the retort is kept at 100 $\mathrm{ml} \mathrm{min}{ }^{-1}$ to sweep generated hydrocarbon vapors away from reaction zone. The reactor temperature controller and set point is selected to $600{ }^{\circ} \mathrm{C}$.

In all runs, a sample of $400 \mathrm{~g}$ of fresh or used lubricating oil soaked ash (contains approximately 200 $\mathrm{g}$ oil) is placed in the retort. The retort temperature increased continuously at uniform rate to the desired final set point. After a period of time of heating, the cracked oil started evolution and/or lubrication oil; these vapors passes through the condenser. The first drop of condensed oil is collect from condenser at 400 ${ }^{\circ} \mathrm{C}$ and this is considered the zero time of the run, the accumulated weight was read and recorded every three minutes during the course run. The ash bed temperature in retort monitored and recorded during run.

The initial collected drops of the product are yellow in color then gradually became darker; at end of run, the color was dark brown. Figure 6 shows the produced oil collected at end of run.

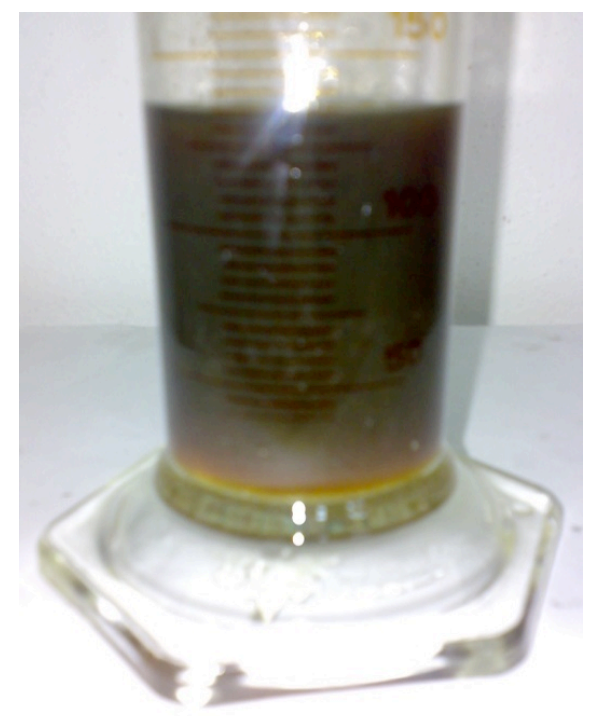

Picture 6: Produced oil from cracking of soaked oil.

The products of fresh and used oil were almost the same. The produced oil was fractionated by distillation to normal petroleum fractions.

\subsection{Part three: Using Steam Instead of Nitrogen}

In this part one layer of ash was used with $500 \mathrm{~g}$ weight and (20-25) $\mathrm{mm}$ particle size, water instead of nitrogen was used as sweep gas after vaporization where it's used as a carrier medium for the produced vapors. And also by repeating the same previous steps the two layers product was collected, these two layers were the condensed oil and the condensed water, which separated before distillation of the product. The two layers shown in the Picture 7:

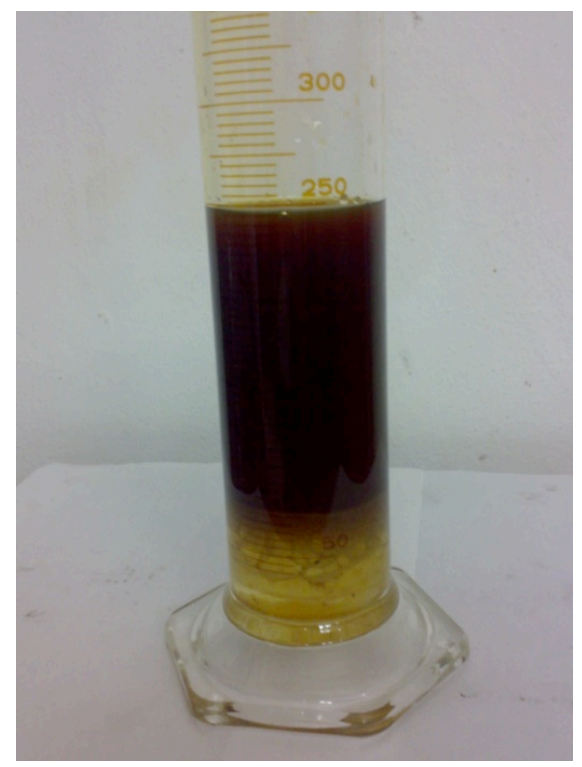

Picture 7: Two layers product for steam runs.

\section{RESULTS AND DISCUSSION}

This research work aims at exploring the possibility of re-using the used lubricating oil in terms of converting these oils to more end use products. The conversion of used lubricating and waste oils to gasoline, kerosene, and diesel using different catalysts is not a new research area but is old as decades. The novel research work in the Present research focuses on utilization of spent shale which is the byproduct of any future oil shale industry in addition, the developed process may implemented in any oil shale industry anywhere.

The present work utilizes the spent shale after calcination and oil soaking steps to catalyzes the cracking of oil in an inert environment to allow cracking to take place.

Used lubricating oil has been impregnated on oil shale ash after calcinations of the spent shale to $950^{\circ} \mathrm{C}$. The calcined ash particles with particle size be between 20 and $25 \mathrm{~mm}$ were soaked in fresh and/or used lubricating oil for more than 24 hours. Initial simple calculations have shown the void in oil shale after calcination increases to a fold, i.e. the voidage volume doubles. Test experiments conducted on the amount of lubricating oil absorbed have indicated that 
ash is impregnated with $100 \%$ weight by weight. Based on this finding, absorbed lubricating oil conversion has been calculated. In order to study the effect of lubricating oil contaminants XRD was used to explore and find any difference in composition of the ash after the cracking process. The generated cracked oil due to the pyrolysis process was sent for simple distillation in Jordan Petroleum Refinery laboratories. The catalytic effect of the mineral content of the oil shale ash on the pyrolysis process has been studied. The effect of steam on the product distribution of the produced oil was also studied and determined.

\section{WEIGHT LOSS MEASUREMENT}

The absorbed lubricating oil on ash is subjected to catalytic cracking in reactor. The used oil undergoes cracking due to the presence of mineral oxides in the ash. The evolved vapors of hydrocarbons from reactor passes through condenser to record rate of weight accumulation as a function of reaction time. Figure 1 shows relationship between reaction time and the rate of product accumulation measured as gmin $^{-1}$. As it can be seen from the Figure 1, that as time of reaction is increased, the rate of liquid production increased to a maximum value. Further increasing reaction time decreased the rate of liquid accumulation. The initial increase in rate of accumulation of products is attributed to increasing reaction temperature and the availability of reactants (kinetic control region) to react whereas, the decrease at longer times of reaction time is ascribed to high reaction temperature and lower reactant concentration due to the depletion of reactants (mass transfer), i.e. absorbed lubricating oils.

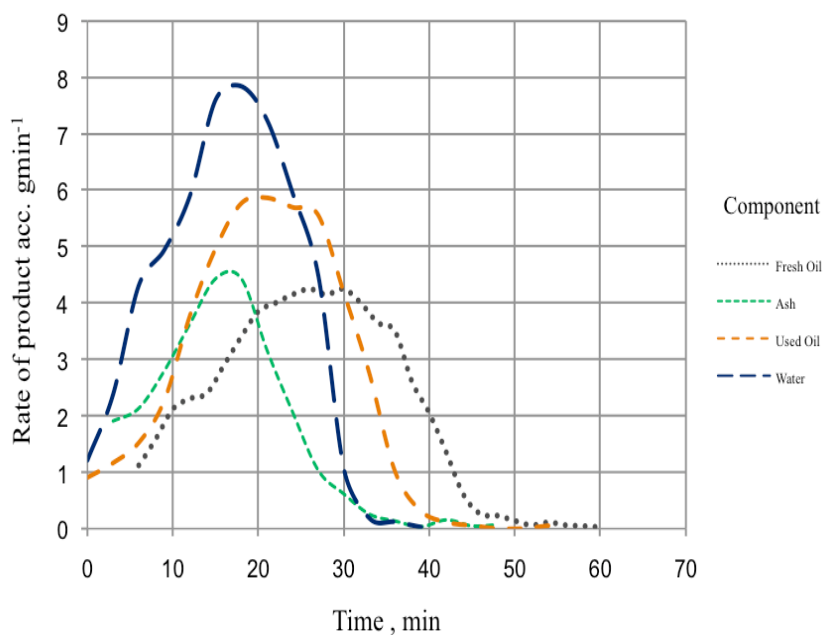

Figure 1: Effect of reaction time on rate of liquid product accumulation, gmin $^{-1}$.

The pyrolysis of the absorbed oil was conducted at constant fixed heating rate for all runs; the reaction temperature was increasing with time to a final value greater than $600{ }^{\circ} \mathrm{C}$. The rate of liquid product accumulation increased to a maximum value ranged from $4.2 \mathrm{gmin}^{-1}$ to $8 \mathrm{gmin}^{-1}$ depending upon the conditions of the pyrolysis process. The reaction environments varied from nitrogen and water vapor as sweeping medium. It is clear from Figure 1, that presence of water vapor in the reaction atmosphere accelerate and increased rate of reaction is which reflected on rate of product accumulation with time.

It should be noted that the rate of an accumulation of products encompasses both water and hydrocarbon condensation rates.

Pyrolysis of absorbed fresh oil resulted in a lower rate of product accumulation and longer time of reaction compared with other conditions. This may be attributed to the nature of fresh oil composition from larger hydrocarbon molecules that is not subjected to heating and reheating processes as the case with used lubricating oils.

Ash run was conducted in a special procedure in which calcined ash was added at the top of the impregnated ash so that the produced cracked oil is subjected to further cracking in the ash layer before exiting reactor. Used oil cracking indicated intermediate rate of liquid accumulation. We feel it is difficult to explain these results in absence of gaseous analysis and X-ray analysis of the used ash after the pyrolysis process. The maximum rate was observed at times higher than 15 minute and less than 30 minute.

\section{CONVERSION OF USED LUBRICATING OIL}

The conversion of impregnated oil on calcined oil ash is shown in Figure 2. The total weight loss of the oil as function of the weight of collected oil is constant as indicated in Figure 1. The gaseous losses decreased with increasing the weight of collected oil during the experiment. The decrease is $10 \%$ while total weight loss is constant for the same conditions. This could be explained on the basis of cracking reactions which produces gases and carbon deposits on the ash surface. This explanation could not be confirmed in absence of measurement of calorific value of the used ash and X-ray analysis. Also it can be seen that the total weight and gaseous losses are increased more when an ash layer was used as a catalytic bed on top of the impregnated ash. This is an indication of the secondary reactions that possibly taking place on the catalyzing components of the ash. The gaseous losses 
were one fold and the total weight loss has increased from $70 \%$ to about $80 \%$.

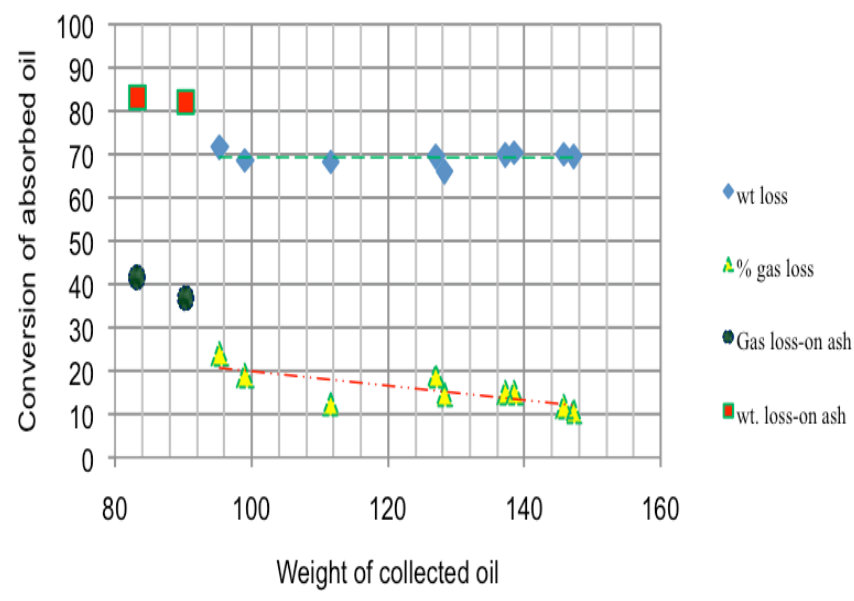

Figure 2: Losses of absorbed oil versus weight of collected liquid.

\section{DISTILLATION DATA}

The produced cracked oil was sent for simple distillation. Distillation results indicated that $60 \%$ of produced oil is recovered up to $370{ }^{\circ} \mathrm{C}$ distillation temperature, while $40 \%$ are considered as residue. The obtained results have been depicted on Figure 3. As it can be seen from Figure 3, that the initial boiling point in all sample almost close to $175^{\circ} \mathrm{C}$ and higher.

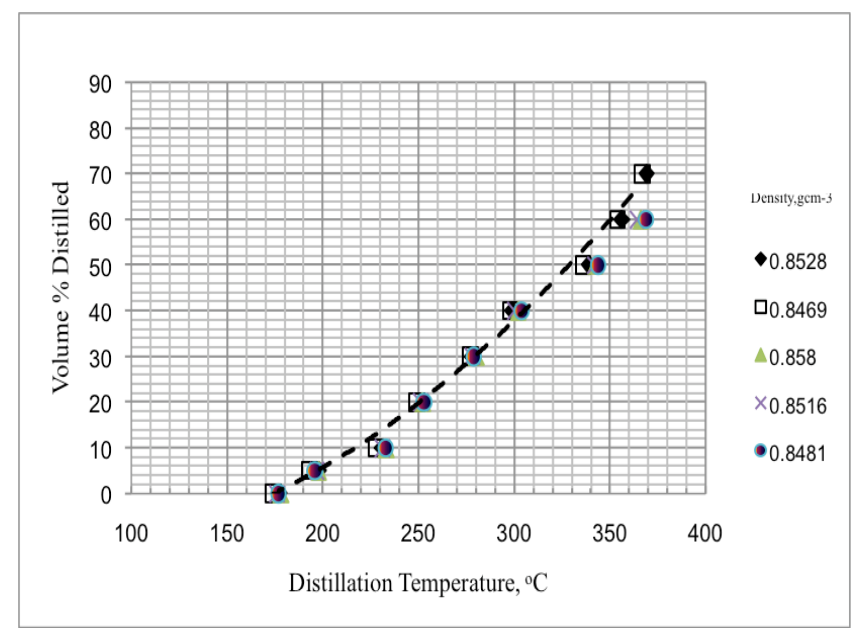

Figure 3: Volume percent distilled versus distillation temperature.

The high initial boiling point indicates absence of naphtha and gasoline fraction in the generated oil. Also Figure 3 presents the density of the different samples used in distillation.

In order to amplify the effects of ash layer and steam presence in the reactions environment on the produces oil, Figure $\mathbf{4}$ shows the volume percent distilled versus distillation temperature. It can be seen that at low distillation temperature the ash has produced more of light components than steam whereas steam produced more of volume percent distilled at high distillation temperature as indicated in Figure 4 at $250^{\circ} \mathrm{C}$ and higher values.

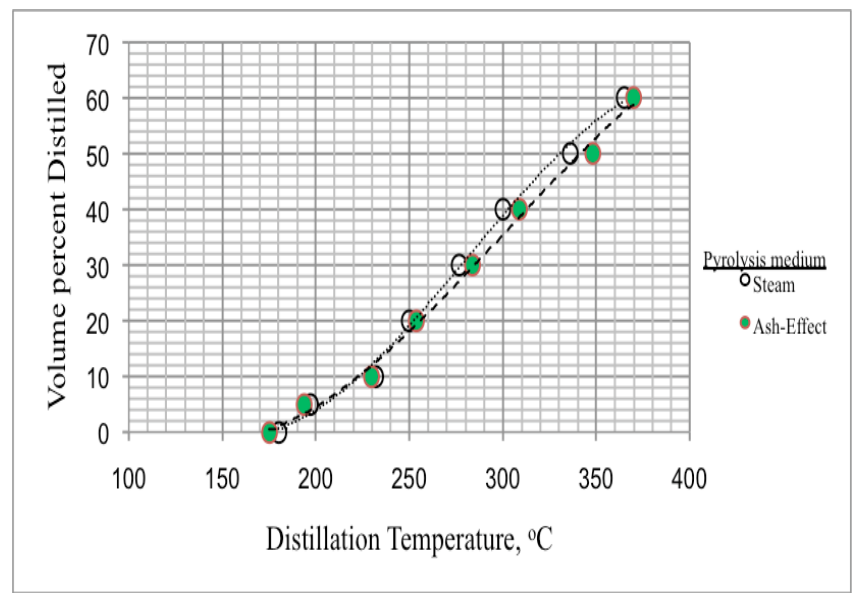

Figure 4: Effect of steam and ash on the produced oil.

These results are attributed to the catalytic effect of oil-free ash on oil and the reactivity of water during reaction. On the other hand, Figure 5 shows that the volume percent distilled for fresh and used impregnated oils did not indicate any influences on the produced nature of oil. These results are indicative of the nature of the lubricating oil which do not undergoes any major chemical changes beside the physical changes during the lubrication process of moving machine parts.

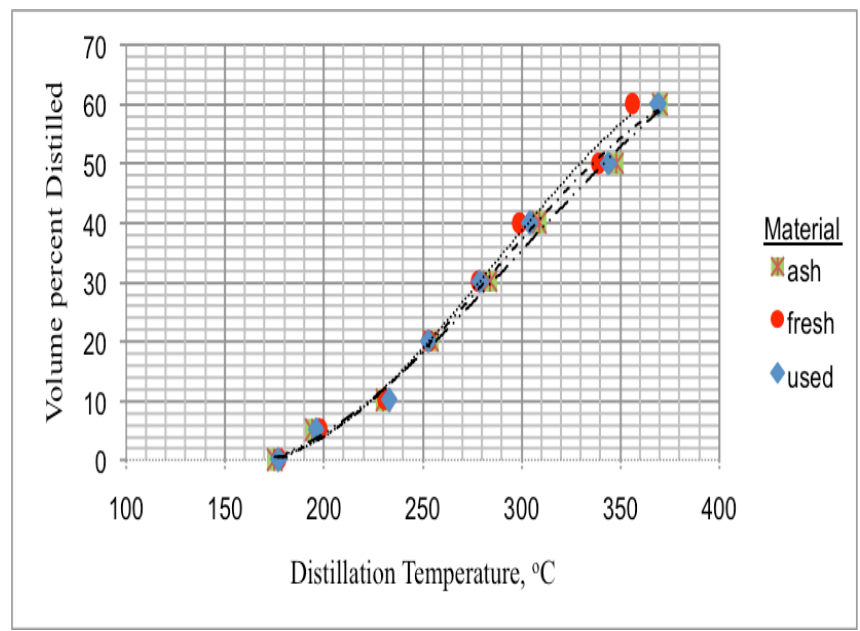

Figure 5: Volume \% distilled and temperature for fresh and used oils.

The distillation data and fractionation to different normal cuts is shown in Figure 6 . The produced oil due to cracking of lubrication oils is fractionated to kerosene 
Table 6.1: Temperature Ranges of Petroleum Cut Fractions

\begin{tabular}{|c|c|c|}
\hline Fraction & Temperature Range, ${ }^{\circ} \mathbf{C}$ & Volume $\%$ \\
\hline \hline Naphtha and Gasoline & $0-140$ & 20 \\
\hline Kerosene & $140-250$ & 50 \\
\hline Diesel & $250-370$ & 30 \\
\hline Residual & $>370$ & 0 \\
\hline
\end{tabular}

and diesel and residual. In crude oil distillation, the normal simple distillation to standard fractions or cuts indicated in the Table 6.1, in comparison, it can be seen from Figure $\mathbf{6}$, that the main fractions of the simple distillation are diesel and kerosene in addition to residue that boils at temperature higher than $370{ }^{\circ} \mathrm{C}$. As shown in Figure 6, the kerosene is in the proximity of $20 \mathrm{vol} \%$; while diesel fraction varied between $45 \%$ to $50 \%$ volume depending upon variation in experimental conditions.

The residue as defined earlier is $30 \mathrm{vol} \%$; which is made of higher molecular weight hydrocarbon that can be used after catalytic cracking to produce lighter hydrocarbons for gasoline, kerosene and diesel production.

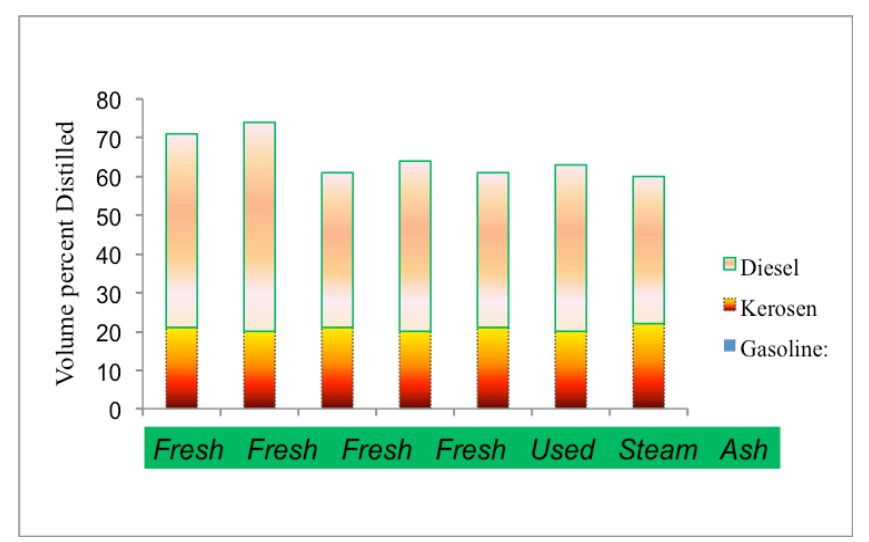

Figure 6: Distillation fractions as function of experimental conditions.

The differences in density of the produced oil are shown in Figure 7, differences in measured densities is reported due to experimental catalyst and reaction environmental operating conditions. The lightest value of density which is equal to 0.8282 gram per cubic centimeter is reported for the oil produced and then allowed to undergo secondary cracking in ash fixed bed placed on top of the original impregnated ash. The highest value of density (more dense) is reported for oil produced in presence of external source of steam. The differences are surmised due to reaction of sweeping medium on the kinetics of the reactions taking place.
Steam could react with hydrocarbons in presence of ash to produce heavier hydrocarbon molecules responsible for increase in density. While in absence of sweeping gas, further secondary cracking reactions may take place to produce coke, lighter hydrocarbon liquids and $\mathrm{C}_{1}-\mathrm{C}_{4}$ hydrocarbon gases.

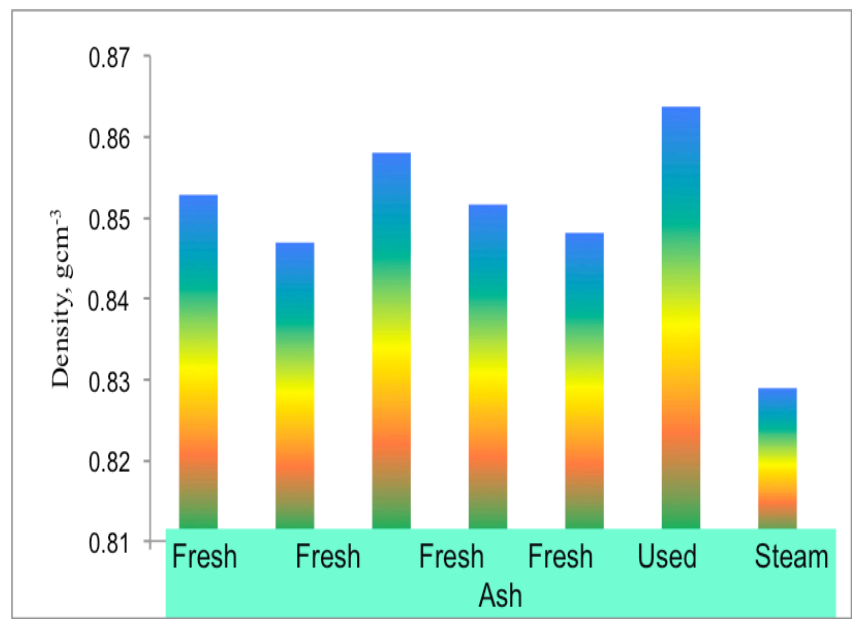

Figure 7: Density variations with experimental components.

Sulfur presence in the produced oil was investigated. Since there is one source of impregnated oil in this work, the original sulfur content of the samples is same; all sample indicated same sulfur percent which is close to $0.75 \%$ wt.

\section{CONCLUSION}

The cracking of used lubricating oils and/or fresh unused waste oils on oil shale ash is achieved and was successful. The reaction is conducted at $600{ }^{\circ} \mathrm{C}$ with different reaction environment. The particle size was in the range of $20-25 \mathrm{~mm}$. The product analysis indicate that $20 \%$ of the liquid product falls in the kerosene fraction specifications whereas approximately $50 \%$ is diesel cut. Residue which boils at higher than $370{ }^{\circ} \mathrm{C}$ constituted about $30 \%$ of the liquid distillate.

The reaction environment has little impact on the product distribution and that could not be studied and determined correctly in absence of the appropriate 
equipment. The gas product distribution also could not be analyzed due to lack of HPLC and similar equipment.

\section{ACKNOWLEDGEMENT}

This work is conducted with support of Al-Balqa Applied University during the sabbatical year in Mutah University.

\section{REFERENCES}

[1] Vestraete JJ, Le Lannic K, Guibard I. Chem Eng Sci 2007; 62: 5402 http://dx.doi.org/10.1016/j.ces.2007.03.020

[2] Linnard RE, Henton LM. Hydrocarbon Processing 1979; 58(9): 148.

[3] Sequeira A, Sherman PB, Douciere JU, McBride EO. Hydrocarbon 1979; 58(9): 155.

[4] Reynolds JW, Whisman ML, Thompson CJ. Hydrocarbon Processing 1977; 56 (9): 128.

[5] Kim MS, Hwang JS, Kim HR. Journal of Environmental Science \& Health, Part A: Environmental Science \& Engineering \& Toxic \& Hazardous Substance Control 1997; 32 (4): 1014. http://dx.doi.org/10.1080/10934529709376593

[6] Hwang JS, Kim HR, Kim MS. Proceedings of the Fourth Japan-Korea Symposium on Separation 1996; 2: 681.

[7] Liou TH, Chang FW, Lo JJ. Industrial Engineering and Chemical Research 1997; 36: 568. http://dx.doi.org/10.1021/ie9604536

[8] Reina J, Velo E, Puigjaner L. Industrial Engineering and Chemical Research 1998; 37: 4290. http://dx.doi.org/10.1021/ie980083g

[9] Kim SS, Yun WL, Kim SH. Journal of Korea Solid Wastes Engineering Society 1998; 15(6): 685.
[10] Dog an O"M, Uysal BZ. Fuel 1996; 75(12): 1424. http://dx.doi.org/10.1016/0016-2361(96)00089-0

[11] Ballice L. Yuksel M. Saglam M. Schulz H. Fuel 1997; 76(5): 375.

[12] Prakash K. Fuel Processing Technology 1997; 51: 83. http://dx.doi.org/10.1016/S0378-3820(97)00002-7

[13] Nerin C, Domeno C, Moliner R, Lazaro MJ, Suelves I, Valderrama J. Behaviour of different industrial waste oils in a pyrolysis process: metals distribution and valuable products. J Anal Appl Pyrol 2000; 55: 171-183. http://dx.doi.org/10.1016/S0165-2370(99)00097-2

[14] Sına`A, Gulbay S. Uskana B, Ucar S. Ozgurler SB. Production and characterization of pyrolytic oils by pyrolysis of waste machinery oil. J of Hazardous Materials 2010; 173 420-426.

http://dx.doi.org/10.1016/j.jhazmat.2009.08.100

[15] Permsubscul A. Vididsant T, Lavarez SD. Catalytic cracking reaction of used lubricating oil to liquid fuels catalyzed by sulfated zirconia. Korean journal of Chemical Engineering 2007; 24(1): 37-43. http://dx.doi.org/10.1007/s 11814-007-5006-3

[16] Linnard RE, Henton LM. Re-refine waste oil with PROP. Hydrocarbon Processing 1979; 58: 148.

[17] Prasad YS, Bakhshi NN. Catalytic conversion of canola oil to fuels and chemical feedstocks: Part II. Effect of co-feeding steam on the performance of HZSM- 5 catalyst. Can J Chem Eng 1986; 64: 285. http://dx.doi.org/10.1002/cjce.5450640219

[18] Bhaskar T, Md Azhar Uddin, Muto A. Sakata Y. Omura Y. Kimura K. Kawakami Y. Recycling of waste lubricant oil into chemical feedstock or fuel oil over supported iron oxide catalysts. Fuel 2004; 83: 9-15. http://dx.doi.org/10.1016/S0016-2361(03)00216-3

[19] Corma A, Miguel PJ, Orchilles AV, Koermer G. Zeolite Effects on the Cracking of Long Chain Alkyle Aromatics 1994; 145(1): 81-186.

[20] Lee KH, Lee. Ha BH. Catalytic Cracking of Vacuum Gas Oil on Alumina/zeolites Mixtures. Korean J Chem Eng 1998; 15(5): 533-537.

http://dx.doi.org/10.1007/BF02707105

DOI: http://dx.doi.org/10.15377/2409-5818.2014.02.01.4

(C) 2014 Omar Al-Ayed; Avanti Publishers.

This is an open access article licensed under the terms of the Creative Commons Attribution Non-Commercial License (http://creativecommons.org/licenses/by-nc/3.0/) which permits unrestricted, non-commercial use, distribution and reproduction in any medium, provided the work is properly cited. 